\title{
COVID-19 lockdowns reduce the Black carbon and polycyclic aromatic hydrocarbons of the Asian atmosphere: source apportionment and health hazard evaluation
}

\author{
Balram Ambade ${ }^{1}$ (D) $\cdot$ Tapan Kumar Sankar $^{1} \cdot$ Amit Kumar $^{1} \cdot$ Alok Sagar Gautam² $^{2}$ \\ Sneha Gautam ${ }^{3}$
}

Received: 30 October 2020 / Accepted: 15 December 2020 / Published online: 3 January 2021

(c) The Author(s), under exclusive licence to Springer Nature B.V. part of Springer Nature 2021, corrected publication, 2021

\begin{abstract}
The entire world is affected by Coronavirus disease (COVID-19), which is spreading worldwide in a short time. India is one of the countries which is affected most, therefore, the Government of India has implemented several lockdowns in the entire country from April 25, 2020. We studied air pollutants (i.e., $\mathrm{PM}_{2.5}$, Black Carbon (BC), and Polycyclic Aromatic Hydrocarbons (PAHs) level, and observed significantly sudden reduced. In India, most of the anthropogenic activities completely stopped. Therefore, we studied the levels of $\mathrm{BC}, \mathrm{PAHs}$ and $\mathrm{PM}_{2.5}$ concentrations, their sources apportion, and health risk assessment during normal days, lockdown (from lockdown 1.0 to lockdown 4.0) and unlock down 1.0 situation at Sakchi, Jamshedpur city. It was observed that lockdowns and unlock down situations $\mathrm{BC}$, PAHs and $\mathrm{PM}_{2.5}$ concentrations were significantly lower than regular days. We applied the advanced air mass back trajectory (AMBT) model to locate airborne particulate matter dispersal from different directions to strengthen the new result. The diagnostic ratio analyses of $\mathrm{BC}$ shows that wood burning contribution was too high during the lockdown situations. However, during normal days, the PAHs source profile was dedicated toward biomass, coal burning, and vehicle emission as primary sources of PAHs. During the lockdown period, emission from biomass and coal burning was a significant contributor to PAHs. The summaries of health risk assessment of $\mathrm{BC}$ quantified an equal number of passively smoked cigarettes (PSC) for an individual situation was studied. This study focuses on the overall climate impact of pandemic situations.
\end{abstract}

Balram Ambade

bambade.chem@nitjsr.ac.in

$\bowtie$ Alok Sagar Gautam

phyalok@gmail.com

Sneha Gautam

gautamsneha@gmail.com

1 Department of Chemistry, National Institute of Technology, Jamshedpur 831014, Jharkhand, India

2 Department of Physics, Hemvati Nandan Bahuguna Garhwal University, Srinagar, Garhwal, Uttarakhand 246174, India

3 Karunya Institute of Technology and Sciences, Coimbatore 641114, Tamil Nadu, India 


\section{Graphic abstract}

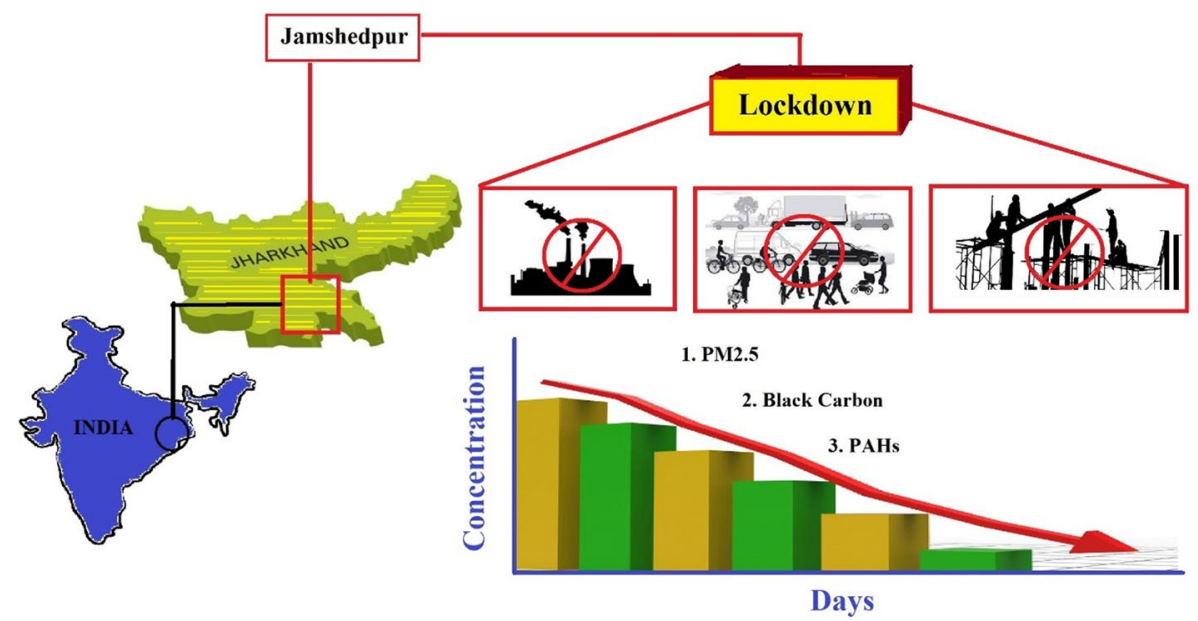

Keywords COVID-19 $\cdot$ Black carbon $\cdot$ PAHs $\cdot$ Backward trajectory $\cdot$ Health risk assessment

\section{Introduction}

The world is facing an extremely challenging situation due to the feast of coronavirus disease (COVID-19) infectious diseases caused by a recently discovered coronavirus. Based on the increasing rate of COVID-19 worldwide, the World Health Organization (WHO) has announced the COVID-19 as an 'international pandemic'. The government of many countries declared lockdown in their countries as a containment strategy after mid of March. According to WHO, 215 countries were seriously affected by a coronavirus (COVID-19) disease before June 1, 2020. Due to COVID-19 diseases, over 6.2 million infection cases and 374,229 death were conformed reported throughout the world (WHO 2020b). The first COVID-19 positive person was confirmed reported on January 30, 2020, in India, and the first death was confirmed reported on March 12, 2020 (WHO 2020a). COVID-19 is still increasing day-to-day in India. Due to this pandemic scenario, India's Prime Minister declared a public curfew on March 22, 2020. Furthermore, India (GoI) government announced a nationwide lockdown (phase I) for more than half a month (21 days) that started from March, 25 to April 1 4, 2020. Phase II was for 19 days from April, 15 to May 3, 2020. Phase III \& IV was for 14 days each i.e., started from 4th May to 31st May 2020. To control COVID-19, GoI recommended the Indian states and citizens to stringently maintain the social distancing ways as a precautionary tactic. Although on one side, the COVID-19 outbreak was an extreme condition for human life, on the other side, it has had specific positive influences on the natural situation. In this present work, we had evaluated the effect on the atmospheric concentration of various pollutants such as black carbon (BC), and Polycyclic Aromatic Hydrocarbons (PAHs)) during regular days, different phases of lockdown, and unlock down 1.0. 
The $\mathrm{BC}$ and PAHs are major constitutes of $\mathrm{PM}_{2.5}$ in the atmosphere. $\mathrm{BC}$ and organic carbon (OC) are two essential components of carbonaceous aerosols, which are the most significant segments of airborne particles (Prasad et al. 2018). Some new studies reported that $\mathrm{BC}$ might be second-most elevated compared to the greenhouse effect (GHE) and $\mathrm{CO}_{2}$ (Liu et al. 2018). Furthermore, BC is also responsible for glacier melting due to its deposition on snow's surface (Prasad et al. 2018). BC has the physical property to absorb visible light because of its dark or intense black color (Cachier 1995; Hansen et al. 1984). As a result, it produces a strong heating effect in the Himalayan-Tibetan region (Lau et al. 2010). BC can serve as CCN (cloud condensation nuclei) and affect clouds' microphysical properties when it is mixed with water-soluble aerosol compositions (Riemer et al. 2010; Rose et al. 2011). Due to smaller size and irregular morphology, BC may cause severe health problems such as mutagenic/carcinogenic pollutants like polycyclic aromatic hydrocarbons (PAHs) and can penetrate deeply into the bronchial part (Janssen et al. 2012). Day-to-day BC emissions have been increasing due to energy demands, industrialization, urbanization, uncontrolled agricultural waste burning, and forest fires in the East and South Asia region (Rastogi et al. 2016; Vadrevu et al. 2015). According to Ramanathan and Carmichael 2008, BC emitted 20\% from bio-fuel burning, 40\% from open biomass burning and fossil fuel burning. Previous research reported that Asia was the highest BC emission producer in 2000 (Ohara et al. 2007).

Polycyclic aromatic hydrocarbons (PAHs) are organic chemical pollutants with two or more aromatic-fused rings fused (Arey and Atkinson 2003; IARC 1984). PAHs are emitted from both natural and anthropogenic processes. In atmosphere, chief natural sources of PAHs are volcanic eruption fires and forest fires (Baek et al. 1991) while primary anthropogenic sources are coal combustion, biomass burning, petroleum, coke and metal production, etc. (Zhang and Tao 2008). Mainly PAHs are emitted from vehicle emission (Bull 2003; Liu, Liu, Lin, Mostert et al. 2010; Wang et al. 2007), industrial activities, during energy production, and incomplete burn of carbonaceous materials (Xu et al. 2006; Cristale et al. 2012). The study of PAHs receives significant concerns from the last few decades because of its harmful properties such as carcinogenic, teratogenic, and mutagenic properties (Boeuf et al. 2016). Almost 95\% of PAHs are associated with size below $3 \mu \mathrm{m}$ (Venkataraman et al. 1994).

In this study, we assessed the variation in $\mathrm{BC}, \mathrm{PM}_{2.5}$ and $\mathrm{PAH}$ data in Jamshedpur city, India during normal days, lockdown 1.0, lockdown 2.0, lockdown 3.0, lockdown 4.0, and unlock down 1.0 in the COVID-19 pandemic. This study helps to understand the conditions of atmosphere, sources appropriation, and health risk assessment of Jamshedpur city during COVID-19 (Table 1).

\section{Sampling site}

BC measurements were made in the Sakchi, Jamshedpur city (220 80' N Longitude and $86020^{\prime}$ E Latitude), located in the southern part of Jharkhand, India. Sakchi is the heart of Jamshedpur. The city stretches over the Chota Nagpur Plateau (CNP) area and covers approximately $6500 \mathrm{~km} 2$. Sackhi is the central part of Jamshedpur and is a very densely populated area. The total population of the city of Jamshedpur is around 1.3 million (according to the 2011 census). The city of Jamshedpur is surrounded on one side by the Dalma Hills which include dense forested areas, green mountains, and world-renowned large industrial conglomerates such as TATA Motors and TATA Iron and Steel Company 
Table 1 BC, $\mathrm{PM}_{2.5}$ and PAHs concentrations data of normal days, different lockdown situations, and unlock down situations at Sakchi, Jamshedpur

\begin{tabular}{|c|c|c|c|c|c|c|c|c|c|c|c|c|}
\hline & \multicolumn{4}{|l|}{$\mathrm{BC}$} & \multicolumn{4}{|l|}{$\mathrm{PM}_{2.5}$} & \multicolumn{4}{|l|}{ PAHs } \\
\hline & Min & Max & Mean & SD & Min & Max & Mean & SD & Min & Max & Mean & SD \\
\hline ND & 6.61 & 16.45 & 9.40 & 2.73 & 91.67 & 205.67 & 136.26 & 32.16 & 128.81 & 150.52 & 135.70 & 24.60 \\
\hline LD 1.0 & 1.19 & 2.44 & 1.85 & 0.36 & 26.37 & 62.61 & 41.39 & 8.33 & 12.81 & 16.04 & 14.92 & 03.84 \\
\hline LD 2.0 & 1.31 & 2.79 & 2.24 & 0.55 & 25.39 & 69.88 & 43.75 & 12.45 & 15.97 & 16.46 & 16.19 & 02.81 \\
\hline LD 3.0 & 1.07 & 3.35 & 2.69 & 0.71 & 29.11 & 58.00 & 45.50 & 9.14 & 14.52 & 16.91 & 15.46 & 05.85 \\
\hline LD 4.0 & 2.25 & 5.27 & 4.11 & 1.02 & 30.41 & 79.35 & 52.99 & 16.21 & 33.62 & 42.23 & 16.16 & 10.56 \\
\hline ULD 1.0 & 2.97 & 9.64 & 5.64 & 1.68 & 59.34 & 120.54 & 86.48 & 15.77 & 53.60 & 66.32 & 61.42 & 15.95 \\
\hline
\end{tabular}

$\mathrm{ND}=$ Normal Days, LD 1.0=Lockdown 1.0, LD 2.0=Lockdown 2.0, LD 3.0=Lockdown 3.0, LD 4.0 = Lockdown 4.0 and ULD 1.0= Unlock down 1.0

(TISCO). The Adityapur Industrial Development Authority (AIDA) area is also located in the city of Jamshedpur. More than 1000 industries (small, medium, and large industries) operate in Adityapur in the AIDA region. The main source of pollution in this area is emissions from city building construction, traffic emissions, road construction, and industrial activities. The map of the sampling location is shown in Fig. 1. Due to the large number of industries and road networks that are the main source of BC, PM2.5 and PAH in the atmosphere of the city of Jamshedpur. BC, PAHs, and PM2.5 aerosols were monitored in three situations (normal days, different lockdown, and unlock down situations) environment or we can say that six situations, i.e., normal days (ND), lockdown 1.0 (LD 1.0), lockdown 2.0 (LD 2.0), lockdown 3.0 (LD 3.0), lockdown 4.0 (LD 4.0), and unlock down 1.0 (ULD $1.0)$.

\section{Measurements and methodologies}

\subsection{Measurement of $\mathrm{BC}$ mass concentrations}

The various essential methodologies to measure the $\mathrm{BC}$ mass concentration compared to other techniques like particle soot absorption photometer, thermal oxidation/reflectance,

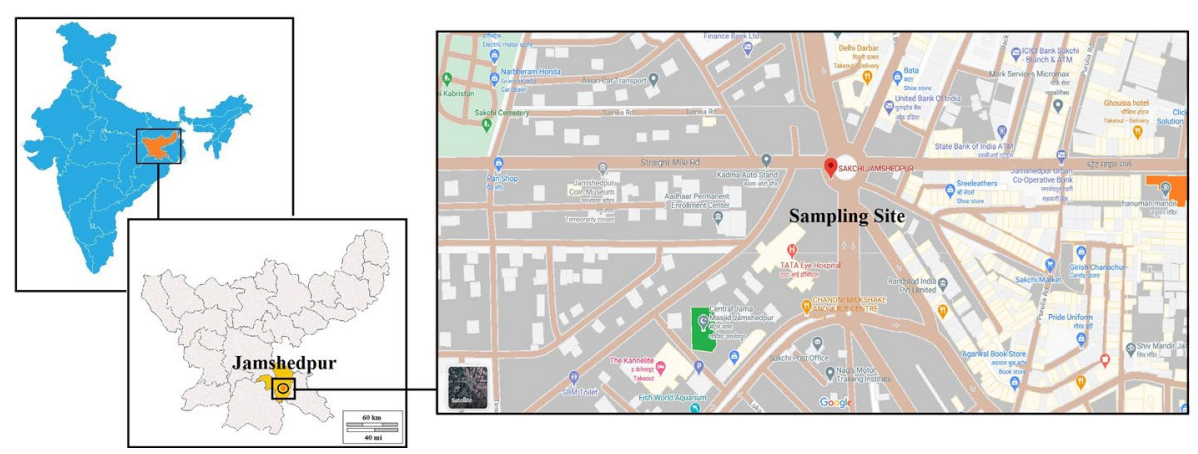

Fig. 1 Satellite aerial view of the sampling site at Sakchi, Jamshedpur city 
coefficient of haze tape sample, etc. (Allen et al. 1999). Aethalometer is the most straightforward technique to measure the $\mathrm{BC}$ mass concentrations because, the mass concentration of $\mathrm{BC}$ aerosol is measured with the help of seven different wavelengths $370 \mathrm{~nm}, 470 \mathrm{~nm}$, $525 \mathrm{~nm}, 590 \mathrm{~nm}, 660 \mathrm{~nm}, 880 \mathrm{~nm}$, and $940 \mathrm{~nm}$. This technique is based on a filter that methods the attenuation of light because the particle's mass is deposited on a filter. The air inlet was fitted to the roof of the building. Atmospheric air pumped over an inlet at the flow rate (nearby 5 LPM) that collides on a quartz filter. BC mass concentrations were reported on the time basis of every $5 \mathrm{~min}$. According to recent research, $880 \mathrm{~nm}$ is the standard wavelength for measuring $\mathrm{BC}$ mass concentration because $\mathrm{BC}$ is the main absorber of light in this particular wavelength; further, aerosol components have unrelated absorption (Weingartner et al. 2003). At $880 \mathrm{~nm}$, a light beam from an extraordinary-intensity light-emitting-diode lamp was transferred over the sample collected on the filter strip. Continuous real-time observation of BC mass concentrations was performed from three different situations i.e., normal days, lockdown (from LD 1.0 to LD 4.0), and unlock down situations. Lockdown and unlock down situations were entirely affected by the COVID-19 pandemic.

\subsection{Measurement of $\mathrm{PM}_{2.5}$ and PAHs concentrations}

The sampling was conducted using a mini volume sampler (Envirotech Model APM 550) operating at a continuous flow rate of $16.5 \mathrm{~L} / \mathrm{m}^{3}$. PTFE filter $(47 \mathrm{~mm}$, Merck, catalog noPM2547050) was used to collect particulate associated PAHs. Before examining, the filter was weighed and kept in a desiccator. Weight balance having a single pan-top loading digital weight balance (VWR, Model no: VWR1611-2263: with Weighing Chamber $\mathrm{L} \times \mathrm{W} \times \mathrm{H}$ : $162 \times 171 \times 225 \mathrm{~mm})$ was used. The foundation contamination was checked using operational blanks (unexposed filters), which were handled simultaneously with field tests. Furthermore, the sample filter was kept in a culture box. These samples were retained at $4{ }^{\circ} \mathrm{C}$ for preservation. The sample was kept in the refrigerator until analysis. In this study, a total of 16 PAHs were analyzed. 16 priority USEPA-PAHs were extracted using soxhlet extraction. To avoid dust loss, the filter was divided into two or more pieces and put into $200 \mathrm{~mL}$ distillation vessels for $10 \mathrm{~h}$. Using the dichloromethane (DCM) solvent in which the extraction cap is primarily dropped and illustrations almost more than $97 \%$ recovery rates. After the extraction process was done. The extracted volume was decreased to $10 \mathrm{~mL}$ by rotary evaporator. The temperature of the chiller was maintained for condensing DCM. The solvent boiling of the, such that the entire extraction period is decreased whereas the vaporized solvent reduces rapidly for reprocessing, dropping the amount of total solvent necessary. Sodium sulfate-silica gel column (glass column of $30 \mathrm{~cm}$ long and $3 \mathrm{~cm}$ in diameter) was used for extract purification. Further, 99\% pure nitrogen gas was used again and again to reduce the volume of purified extract up to 1-2 $\mathrm{mL}$ and then quantified by advanced Gas Chromatography (GC- FID, Agilent 7890B) coupled with a flame ionization detector (FID) equipped with capillary column HP- 5MS $(30 \mathrm{~m} \times 0.25 \mathrm{~mm}$ i.d $\times 0.25 \mu \mathrm{m})$. Nitrogen gas was used as carrier gas with a flow rate of $2 \mathrm{~mL} \mathrm{~min}^{-1}$. In the splitless mode, $1 \mu \mathrm{L}$ of each sample was injected into GC-FID. The oven temperature was started at $60{ }^{\circ} \mathrm{C}$ for $3 \mathrm{~min}$ and increased up to $320{ }^{\circ} \mathrm{C}$ at a rate of $5{ }^{\circ} \mathrm{C} \mathrm{min}{ }^{-1}$ and kept for $20 \mathrm{~min}$. The 16 USEPA priority PAH concentrations were quantified with the help of the peak area of spectra and retention time. The field and laboratory blank samples were isolated and then examined similarly to the field sample. The PAH compound was not identified in the blank samples. 


\subsection{Source apportionment method of BC mass concentration and PAHs}

In this study, a handy aethalometer was used to reveal the source apportionment of BC mass concentration. Many methods were used to clarify the source apportionment of BC mass concentration, such as positive matrix factorization (PMF), the macro-tracer method, principal component analysis (PCA), chemical mass balance (CMB), the aethalometer model, and other specialized models (Florou et al. 2017; Thepnuan et al. 2019; Briggs and Long 2016; Belis et al. 2013; Larsen et al. 2012; Favez et al. 2010). But Aethalometer is one of the easiest methods. This model characterizes fewer source-category (e.g., traffic emissions and wood burning); however, it only requires a different-wavelength light absorption dataset (Zotter et al. 2017). Significant sources of BC mass concentrations were incomplete combustion of biofuel burning and fossil fuel in the atmosphere. To characterize the $\mathrm{BC}$ mass sources of regional emissions from the sources mentioned above, we must determine the percentage difference in $\mathrm{BC}$ measured at two wavelengths i.e., $\mathrm{BC}_{370}$ and $\mathrm{BC}_{880}$.

$$
\text { i.e., } \% \text { difference of } \mathrm{BC}=\left(\mathrm{BC}_{370}-\mathrm{BC}_{880}\right) / \mathrm{BC}_{880} \text {. }
$$

From Eq. (1), if the percentage difference of $\mathrm{BC}$ value was reported to a negative fraction, it suggested that $\mathrm{BC}$ emission comes out from fossil fuel (e.g., diesel, petrol, etc.). And if a difference in the percentage of $\mathrm{BC}$ value was reported to positive fraction, it suggested that BC emission comes out from wood burning (e.g., domestic use products like coal, forest fire, dry leaf, etc.) (Wang et al. 2011).

We can have characterized the different sources of PAHs from diagnostic ratio analysis. For diagnostic ratio analysis, the biomass burning, coal burning, traffic emission, and industry emissions were analyzed. We also described the fire count data and air backward trajectory to analyses the source apportionment of BC mass concentrations, PAHs, and $\mathrm{PM}_{2.5}$ concentrations.

\subsection{Assessment of health risks of BC}

According to modern scientific studies and current research, exposure to BC may cause serious health issue to humans such as non-cancer (respiratory-related problem, cardiovascular diseases) and cancer (lung cancer) diseases in humans (Niranjan and Thakur 2017; De Prins et al. 2014; Magalhaes et al. 2018). The health risks of passive smoking are equivalent to the health risk of BC (e.g., Muller and Muller 2013; Wu et al. 2018; Van der Zee et al. 2016). Since both show identical characteristics. Mainly three main features show to compare the health risk between passive smoking and BC aerosol, (1) both show alike health effects, (2) contact to environmental tobacco smoke (ETS) and atmospheric BC contamination, and (3) both risks have the similar exposure way, i.e., through inhalation (Van der Zee et al. 2016). According to Van der Zee et al. 2016 had developed a model by which we can easily determine the health hazard evaluation, which is grounded on ETS. The value of ETS was used to calculate the health risk of BC pollution. Four health-related issues were detected with the help of this model. The four health issues are cardiovascular mortality (CM), lung cancer (LC), low birth weight (LBW), and percentage lung function decrement of school-aged children (PLFDSC). All four health-related issues are noticeable by reference to both ETS and BC pollution (Kelly and Fussell 2015; WHO 2014; Oberg et al. 2010). The calculation part of health risk estimation was primarily dependent on relative risks (RRs), 
comparable to a different health issue for ETS exposure and air pollutant like BC; where $\mathrm{RR}$ refers to the prospect of growing an illness induced by contact to air pollutants (WHO 2003; Rothman et al. 2008). The connection between a health-related risk issue and a specified change in $\mathrm{BC}$ aerosol was identified by a meta-analysis of recorded concentration-response functions (CRFs). Since the particular fitness issue (i.e., R), the BC concentration increases by one $\mu \mathrm{g} \mathrm{m}^{-3}$, comparable to the number of passively smoked cigarettes (PSC) (Van der Zee et al. 2016).

Therefore, $\mathrm{R}$ is written as

$$
\mathrm{R}=\left[\ln \left(\mathrm{RR}_{\mathrm{BC}}\right) / \Delta \mathrm{Conc}\right] /\left[\ln \left(\mathrm{RR}_{\mathrm{ETS}}\right) / \text { expected number of PSC }\right]
$$

where $\left[\ln \left(R_{\mathrm{BC}}\right) / \Delta \mathrm{Conc}\right]=$ the consequential risks for variation in $\Delta$ Concentration (i.e., $\left.1 \mu \mathrm{g} \mathrm{m}^{-3}\right)$ of $\mathrm{BC} . \mathrm{RR}_{\mathrm{BC}}=\mathrm{RR}$ of $\mathrm{BC}$ concerning particular health issues. [ $\ln \left(\mathrm{RR}_{\mathrm{ETS}}\right) /$ assumed number of PSC] $=$ the ensuing risks of ETS exposure for the expected number of PSC per day. $R_{E T S}=R R$ of ETS for the particular health issue.

The value of $\mathrm{RR}_{\mathrm{BC}}$ and $\mathrm{RR}_{\mathrm{ETS}}$ is resultant from precisely organized assessments and can be summarized to implement the relevant, yet immature, health hazard estimations. The value of $R_{B C}$ and $R R_{E T S}$ was taken from the selected reference paper (Pani et al. 2020). The expected number of PSC per day is different for different health risk issues. For the child of a non-smoking mother, the expected number of PSC per day is 7 for CVM, LC and LBW (Van der Zee et al. 2016). The assumed number of PSC per day is 9 in the case of PLFDSC. The following formula calculated the corresponding numbers of PSC per day (i.e., NPSC: passive cigarette-equivalence),

$$
\mathrm{NPSC}=\Delta \mathrm{BC} \times \mathrm{R}
$$

And

$$
\Delta \mathrm{BC}=\left[\left(\mathrm{BC}_{\mathrm{rep}}\right)-\left(\mathrm{BC}_{\mathrm{bac}}\right)\right]
$$

where $\mathrm{BC}_{\text {rep }}=$ Reported Black Carbon and $\mathrm{BC}_{\mathrm{bac}}=$ Background Black Carbon.

In this recent study, our aim to reported only health risk estimates of $\mathrm{BC}$ pollution but not reported the inclusive concern of disease because of ETS exposure or BC effluence (Wu et al. 2018), which are accessible to understand for the public as well as the policymakers. Our assessment was depended on the WHO-based review of Van der Zee et al. (2016), where the 14 daily cigarette intake smokers from North-West Europe and the united state (US). In this new study, our target to report the health hazards of atmospheric $\mathrm{BC}$ effluence corresponding to residents of Jamshedpur city in the different situation during the COVID-19 pandemic i.e., for normal days, lockdown (from lockdown 1.0 to lockdown 4.0) and unlock down 1.0 situations, who may be the probable receptor as matched with passive cigarette smoking.

\subsection{Evaluation of health risks due to PAHs}

The health hazard allied with PAHs contact was calculated using the Toxicity equivalent concentration (TEQ) equation (Yu et al. 2008). The equation shows the summation of projected cancer risk related to $\mathrm{BaP}$ for all PAHs having carcinogenic potential, which can be designed by multiplying the concentration of every carcinogenic PAHs and Toxicity equivalence factor (TEF). 


$$
\mathrm{TEQ}=\sum \mathrm{Ci} \times \mathrm{TEFi}
$$

where $\mathrm{Ci}=$ Separate $\mathrm{PAHs}$ concentration and $\mathrm{TEFi}=$ the toxic equivalency factor

TEFi value was given by Nisbet and Lagoy (1992); 0.01 for Phe, Flt, and Pyr; 0.01 value for $\mathrm{Chr}$, Ant, and $\mathrm{B}$ (ghi)P; 0.1 value for $\mathrm{BaA}, \mathrm{BkF}$, and IcP and 1 value for $\mathrm{BaP}$ and DBahA. Moreover, the exposure risk due to individual PAHs can be quantitatively calculated by Incremental lifetime cancer risk (ILCR) (EPA. 1991; U.S. Chen and Liao 2006; Peng et al. 2011). ILCR was measured by considering the corresponding lifetime average daily dose (LADD) of PAHs by allowing for dual age group adults (age 70 years) and children (age 6 years). LADD demonstrates the quantity of uncertain chemical consumption per $\mathrm{kg}$ of body mass per day and harms health when detected by the body for an extended period. The following equation is used for the expression and assessment of LADD and ILCR.

$$
\begin{gathered}
\mathrm{LADD}\left(\mathrm{mg} \mathrm{kg}^{-1} \mathrm{day}^{-1}\right)=(\mathrm{Cs} \times \mathrm{CF} \times \mathrm{IR} \times \mathrm{EF} \times \mathrm{ED}) /(\mathrm{BW} \times \mathrm{AT}) \\
\mathrm{ILCR}=\mathrm{LADD} \times \mathrm{CSF}(\text { Cancer Oral Slope Factor })
\end{gathered}
$$

where C01s means the quantity of PAHs' transformed concentration concerning TEQ assessment in airborne particulate $\left(\mathrm{ng} \mathrm{m}^{-3}\right)$. In the present study, the ILCR value was evaluated for adult and child, where parameters were, $\mathrm{CF}$ means the unit change factor $\left(1 \times 10^{-6} \mathrm{mg} \mathrm{kg}^{-1}\right)$, IR was the air inhalation rate $\left(\mathrm{m}^{3} \mathrm{day}^{-1}\right)$, EF means the exposure frequency (day year ${ }^{-1}$ ), ED means the lifetime exposure period. BW means the Bodyweight $(\mathrm{kg})$, AT means the averaging time for carcinogens (days), and CSF means the inhalation cancer slope factor $\left(3.85 \mathrm{mg} \mathrm{kg}^{-1} \mathrm{day}^{-1}\right)$ (Peng et al. 2011). The detail of the parameter designated in Table 4.

\section{Results and discussion}

\subsection{Black carbon mass concentration variation during the study period}

The satellite study through the GIOVANNI NASA website demonstrated the BC surface mass concentration monthly $0.5 \times 0.625 \mathrm{deg}$. [MERRA-2 Model M2TMNXAER v 5.12.4] $\mu \mathrm{g} \mathrm{m}^{-3}$ at three situations i.e., Normal Days, different lockdown (from lockdown 1.0 to lockdown 4.0), and Unlock down 1.0-situations, as shown in Fig. 2. According to the GIOVANNI NASA website, BC mass concentration was reported to be highest during normal days i.e., approx. $3 \mu \mathrm{g} \mathrm{m}^{-3}$ to $4 \mu \mathrm{g} \mathrm{m}^{-3}$ compared to lockdown situation (from lockdown 1.0 to lockdown 4.0) and unlock down 1.0 situation. In lockdown situation, BC mass concentration was approx. $1.88 \mu \mathrm{g} \mathrm{m}^{-3}$ to $2.77 \mu \mathrm{g} \mathrm{m}^{-3}$ and in the unlock down situation was approx. $2.33 \mu \mathrm{g} \mathrm{m}^{-3}$ to $3.22 \mu \mathrm{g} \mathrm{m}^{-3}$. It was seen that in the unlock down situation, the BC mass concentration was a little bit high as associated with the lockdown situation. This is because during a lockdown situation, all traffic transportation, industries activities were closed, and unlock down situation, most of the traffic transportation and some industries were open. The eastern part and the northern part of Indian had a more BC concentration compared to the rest part of the country i.e., the Indo-Gangetic Plain (IGP) region had more $\mathrm{BC}$ concentration in all three situations. i.e., during normal days, lockdown (from lockdown 1.0 to lockdown 4.0) situations and unlock down 1.0 situation. It was clearly 


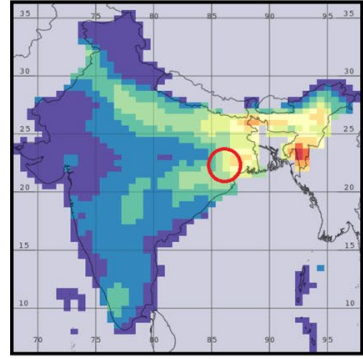

(a) Normal Days (1 Mar - 23 Mar 2020)

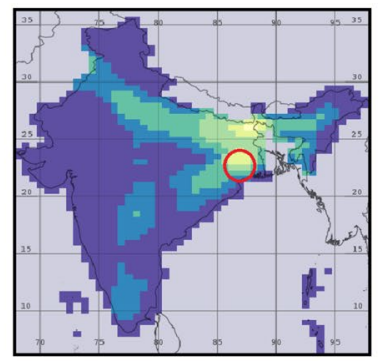

(b) Lockdown 1.0, 2.0, 3.0 and 4.0 (25 Mar-31 May 2020)

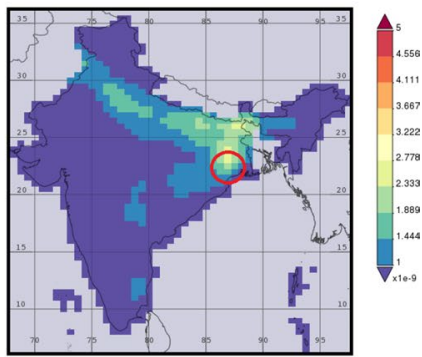

(c) Unlock-down 1.0 ( from 1 Jun - 31 Jun 2020)

Fig. 2 Time average map of Black carbon surface mass concentration monthly $0.5 \times 0.625$ deg. [MERRA-2 Model M2TMNXAER v 5.12.4] $\mu \mathrm{g} \mathrm{m}^{-3}$ at three different situations a Normal Days, b Lockdown 1.0, 2.0, $3.0, \& 4.0$, and $\mathrm{c}$ unlock down 1.0

shown in Fig. 2. Simultaneously, we conducted fieldwork to determine the BC mass concentrations. $\mathrm{BC}$ mass concentrations were analyzed for $12 \mathrm{~h}$ a day during six situations. The averaged $\mathrm{BC}$ mass concentrations were noticed to be about $9.40 \pm 2.73 \mu \mathrm{g} \mathrm{m} \mathrm{m}^{-3}, 1.85 \pm 0.36$ $\mu \mathrm{g} \mathrm{m}{ }^{-3}, 2.24 \pm 0.55 \mu \mathrm{g} \mathrm{m}^{-3}, 2.69 \pm 0.71 \mu \mathrm{g} \mathrm{m}^{-3}, 4.11 \pm 1.02 \mu \mathrm{g} \mathrm{m}^{-3}$ and $5.64 \pm 1.68 \mu \mathrm{g} \mathrm{m}^{-3}$ during normal days, lockdown 1.0, lockdown 2.0, lockdown 3.0, lockdown 4.0, and unlock down 1.0, respectively. On normal days, maximum and minimum BC mass concentrations were $16.45 \mu \mathrm{g} \mathrm{m}^{-3}$ and $6.61 \mu \mathrm{g} \mathrm{m}^{-3}$, respectively. BC's concentration was very high because all activities such as industries, construction work, traffics, roads were working during normal days. In different lockdown situations, BC's maximum and minimum concentration was $1.07 \mu \mathrm{g} \mathrm{m}^{-3}$ (during lockdown 3.0) and $5.27 \mu \mathrm{g} \mathrm{m}^{-3}$ (during lockdown 4.0), respectively. The low $\mathrm{BC}$ mass concentrations were observed because all activities such as construction work, industries work, transportation work, traffic roads were closed during lockdown situations. In unlock down situations, maximum and minimum BC mass concentrations were $2.97 \mu \mathrm{g} \mathrm{m}^{-3}$ and $9.64 \mu \mathrm{g} \mathrm{m}^{-3}$, respectively. During these days, BC's mass concentration was moderate, i.e., neither high as in normal days nor low like lockdown situations. This is because during these days some activities were open like transport work, traffic roads are open but industries work was not fully open and maybe some industries were open. During the whole study, BC mass concentration was varied from 1.07 to 16.45 $\mu \mathrm{g} \mathrm{m}^{-3}$. It was seen that the $\mathrm{BC}$ mass concentration continuously decreased throughout lockdown situations and again a little bit increasing during unlock down situations as revealed in Fig. 3.

\section{2 $\mathrm{PM}_{2.5}$ and PAHs concentration variation during the study period}

Like BC mass concentration, $\mathrm{PM}_{2.5}$ concentrations and 16 PAHs were also determined in different situations i.e., Normal Days, Lockdown 1.0, Lockdown 2.0, Lockdown 3.0, \& Lockdown 4.0, and unlock down 1.0 as shown in Fig. 3. On normal days' maximum and minimum of $\mathrm{PM}_{2.5}$ concentrations were $91.67 \mu \mathrm{g} \mathrm{m}^{-3}$ and $205.67 \mu \mathrm{g} \mathrm{m}^{-3}$, respectively, and the minimum concentration of PAHs was $128.81 \mathrm{ng} \mathrm{m}^{-3}$, and maximum concentration was $150.52 \mathrm{ng} \mathrm{m}^{-3}$. The concentration of $\mathrm{PM}_{2.5}$ and PAHs was high because all activities like industries traffic transport, roads, construction works were open during normal days. In different lockdown situations, minimum and maximum concentrations of $\mathrm{PM}_{2.5}$ were $25.39 \mu \mathrm{g} \mathrm{m}^{-3}$ (during lockdown 2.0) and $79.35 \mu \mathrm{g} \mathrm{m}^{-3}$ (during lockdown 

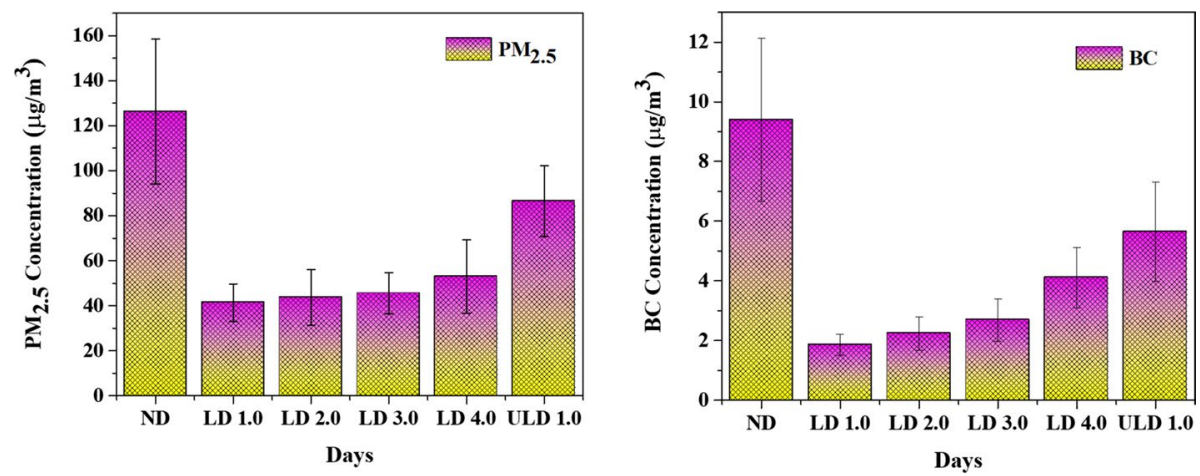

Fig. 3 Mass concentration with stand deviation of $\mathrm{PM}_{2.5}$ and $\mathrm{BC}$ at different situations i.e., normal days (ND), lockdown 1.0 (LD 1.0), lockdown 2.0 (LD 2.0), lockdown 3.0 (LD 3.0), lockdown 4.0 (LD 4.0), and unlock down 1.0 (ULD 1.0) at Sakchi, Jamshedpur

4.0), respectively, and minimum concentration of PAHs was $12.81 \mathrm{ng} \mathrm{m}^{-3}$ (during lockdown 1.0), and maximum concentration was $42.23 \mathrm{ng} \mathrm{m}^{-3}$ (during lockdown 4.0). The low $\mathrm{PM}_{2.5}$ and $\mathrm{PAH}$ concentrations were observed because all activities such as industries work, transportation work, construction work, traffic roads were closed during lockdown situations. In the unlock down situation, maximum and minimum $\mathrm{PM}_{2.5}$ concentrations were $59.34 \mu \mathrm{g} \mathrm{m}^{-3}$ and $120.54 \mu \mathrm{g} \mathrm{m}^{-3}$, respectively, and minimum concentration of PAHs was $53.60 \mathrm{ng} \mathrm{m}^{-3}$ and the maximum concentration was $66.32 \mathrm{ng} \mathrm{m}^{-3}$. During these days the $\mathrm{PM}_{2.5}$ and PAH's concentration was moderate i.e., neither high as in normal days nor low like lockdown situations because during these days in some activities were open, such as transport work, traffic road, etc. but industries work was not fully open, somewhere maybe some industries were open. The averaged $\mathrm{PM}_{2.5}$ concentrations were noticed to be about $136.26 \pm 32.16 \mu \mathrm{g} \mathrm{m}^{-3}, 41.39 \pm 8.33 \mu \mathrm{g} \mathrm{m}^{-3}, 43.75 \pm 12.45 \mu \mathrm{g} \mathrm{m}^{-3}, 45.50 \pm 9.14$ $\mu \mathrm{g} \mathrm{m}{ }^{-3}, 52.99 \pm 16.21 \mu \mathrm{g} \mathrm{m}^{-3}$, and $86.48 \pm 15.77 \mu \mathrm{g} \mathrm{m}^{-3}$ during normal days, lockdown 1.0, lockdown 2.0, lockdown 3.0, lockdown 4.0, and unlock down 1.0, respectively. During the whole study, $\mathrm{PM}_{2.5}$ concentrations were varied from 25.39 to $205.67 \mu \mathrm{g} \mathrm{m}^{-3}$. It was seen that the $\mathrm{PM}_{2.5}$ concentrations were continuously decreasing during lockdown situations (from lockdown 1.0 to lockdown 4.0) and again a little bit increasing during unlock down 1.0 situations as shown in Fig. 3. The averaged PAHs concentrations were noticed to be about $135.70 \pm 24.60 \mathrm{ng} \mathrm{m}^{-3}, 14.92 \pm 3.84 \mathrm{ng} \mathrm{m}^{-3}, 16.19 \pm 2.81 \mathrm{ng} \mathrm{m}^{-3}, 15.46 \pm 5.85$ $\mathrm{ng} \mathrm{m}{ }^{-3}, 16.16 \pm 10.56 \mathrm{ng} \mathrm{m}^{-3}$, and $61.42 \pm 15.95 \mathrm{ngvm}^{-3}$ during normal days, lockdown 1.0, lockdown 2.0, lockdown 3.0, lockdown 4.0, and unlock down 1.0, respectively. And during study of PAHs concentrations was varied from 12.81 to $150.52 \mathrm{ng} \mathrm{m}^{-3}$, and it was seen in Fig. 4 that the PAHs concentrations were continuously decreasing during lockdown situations, and again small numbers of concentrations were increasing during unlock down 1.0 situations.

In all phases of lockdown, the anthropogenic activities were closed. As a result, fewer air pollutants were coming into the atmosphere. In the current study, it was reported that Anthracene (Ant) concentrations were maximum i.e., $11.98 \pm 1.38 \mathrm{ng} \mathrm{m}^{-3}$ and Dibenzo[ah] anthracene (DBahA) concentrations were minimum i.e., $5.82 \pm 0.72 \mathrm{ng} \mathrm{m}^{-3}$ during normal days. During lockdown 1.0 situations, Pyrene (Pyr) concentrations were maximum i.e., $1.18 \pm 0.30 \mathrm{ng} \mathrm{m}^{-3}$, and Naphthalene (Nap) concentrations were minimum i.e., $0.61 \pm 0.16$ $\mathrm{ng} \mathrm{m}^{-3}$. Indeno[123-cd]pyrene (IcP) concentration was maximum i.e., $1.12 \pm 0.13 \mathrm{ng} \mathrm{m}^{-3}$, 
Fig. 4 Concentration $\left(\mathrm{ng} \mathrm{m}^{-3}\right)$ of PAHs at three different situations i.e., normal days (ND), lockdown 1.0-4.0 (LD 1-4), and unlock down 1.0 (ULD 1) situations at Sakchi, Jamshedpur

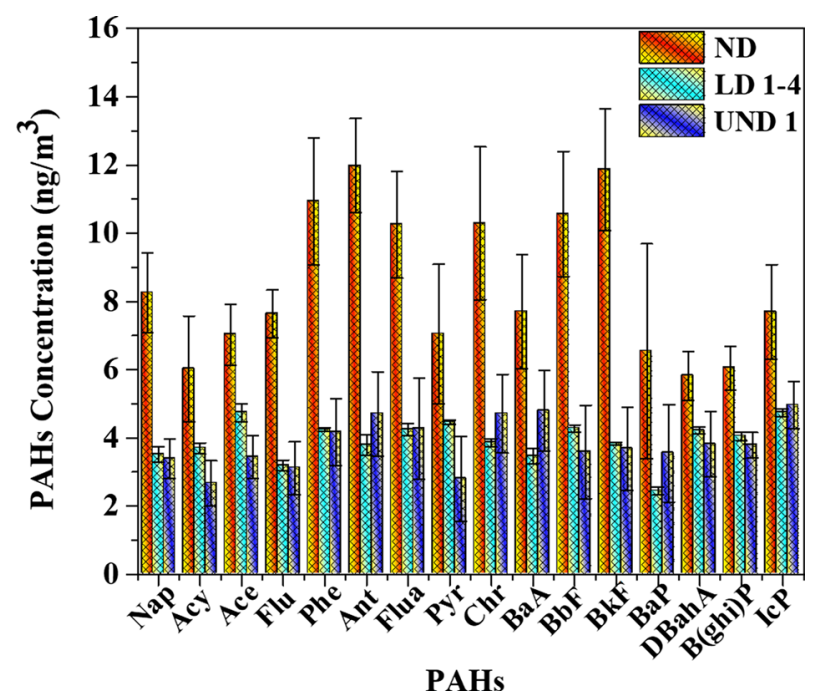

and Benzo[a]pyrene $(\mathrm{BaP})$ concentration was minimum i.e., $0.56 \pm 0.24 \mathrm{ng} \mathrm{m}^{-3}$ in lockdown 2.0 situation, and Acenaphthene (Ace) concentration was maximum i.e., $1.39 \pm 0.37$ $\mathrm{ng} \mathrm{m}^{-3}$, and Benzo[a]pyrene (BaP) concentration was minimum i.e., $0.48 \pm 0.34 \mathrm{ng} \mathrm{m}^{-3}$ in lockdown 3.0 situation. During lockdown 4.0 situations, Indeno[123-cd]pyrene (IcP) concentration was maximum i.e., $1.29 \pm 1.00 \mathrm{ng} \mathrm{m}^{-3}$, and Benzo[a]pyrene (BaP) concentration was minimum i.e., $0.66 \pm 0.0 .41 \mathrm{ng} \mathrm{m}^{-3}$. Indeno[123-cd]pyrene (IcP) concentration was maximum i.e., $4.95 \pm 0.69 \mathrm{ng} \mathrm{m}^{-3}$, and Acenaphthylene (Acy) concentration was minimum i.e., $2.67 \pm 0.66 \mathrm{ng} \mathrm{m}^{-3}$ during unlock down 1.0 situation. The $16 \mathrm{PAH}$ concentrations are reported in Table 2. The regular emission PAHs concentrations in Sakchi, Jamshedpur city was due to local residence burning such as burning coal, wood, biomass, kerosene, traffic emission, industrialization. The whole research study shows that the concentrations of all air pollutants such as $\mathrm{BC}$, PAHs and $\mathrm{PM}_{2.5}$ were decreased during the lockdown as compare to normal days and unlock down situations due to the COVID-19 pandemic.

\subsection{Source apportionment of BC and PAHs concentration}

The sources of $\mathrm{BC}$ mass concentration and PAH concentration may have the same but their technique is different from characterized the source apportionment. The source recognition of BC mass concentration was determined by the aethalometer technique. Although, this model characterized some selective source-category such as wood burning and traffic emissions. According to SAFAR 2010, the burning of coal is a major source of BC mass concentration into the atmosphere, and coal burning is the highest source of energy that supplies $76 \%$ of our requirement in India. An examination of BC estimated at UV (370 nm) frequencies and near IR $(880 \mathrm{~nm})$ frequencies was made, which is great for the source characterization of BC (Srivastava et al. 2012). Bio-fuel consuming and horticulture fires have been perceived as the most significant source of BC over the Indo-Gangetic Basin (IGB) territories (Venkataraman et al. 2006). The source separates between wood-consuming and petroleum products in various circumstances, i.e., ordinary days, lockdown-1.0, lockdown-2.0, lockdown-3.0, lockdown-4.0, and unlock down-1.0-circumstance. The origins of $\mathrm{BC}$ mass concentration are processes, i.e., the natural process such as volcanic 
Table 2 The concentration of PAHs $\left(\mathrm{ng} \mathrm{m}^{-3}\right)$ in six different situations

\begin{tabular}{|c|c|c|c|c|c|c|c|c|c|c|c|c|}
\hline \multirow[t]{2}{*}{ Abbr } & \multicolumn{2}{|l|}{ ND } & \multicolumn{2}{|c|}{ LD 1.0} & \multicolumn{2}{|c|}{ LD 2.0} & \multicolumn{2}{|c|}{ LD 3.0} & \multicolumn{2}{|c|}{ LD 4.0} & \multicolumn{2}{|c|}{ ULD 1.0} \\
\hline & PAHs & SD & PAHs & SD & PAHs & SD & PAHs & SD & PAHs & SD & PAHs & SD \\
\hline Nap & 8.25 & 1.16 & 0.61 & 0.16 & 0.88 & 0.09 & 1.15 & 0.34 & 0.87 & 0.53 & 3.39 & 0.58 \\
\hline Acy & 6.02 & 1.55 & 0.73 & 0.16 & 1.08 & 0.14 & 0.88 & 0.28 & 1.01 & 0.78 & 2.67 & 0.66 \\
\hline Ace & 7.04 & 0.89 & 1.38 & 0.40 & 0.86 & 0.17 & 1.39 & 0.37 & 1.10 & 0.52 & 3.44 & 0.62 \\
\hline Flu & 7.64 & 0.71 & 0.74 & 0.38 & 0.98 & 0.14 & 0.61 & 0.56 & 0.86 & 0.65 & 3.11 & 0.78 \\
\hline Phe & 10.94 & 1.86 & 1.02 & 0.16 & 1.08 & 0.15 & 1.13 & 0.41 & 1.01 & 0.53 & 4.17 & 0.98 \\
\hline Ant & 11.98 & 1.38 & 0.90 & 0.09 & 1.34 & 0.20 & 0.63 & 0.42 & 0.92 & 0.57 & 4.71 & 1.24 \\
\hline Flua & 10.25 & 1.56 & 0.82 & 0.22 & 1.06 & 0.20 & 1.24 & 0.49 & 1.12 & 0.75 & 4.27 & 1.49 \\
\hline Pyr & 7.04 & 2.05 & 1.18 & 0.30 & 1.09 & 0.14 & 1.14 & 0.40 & 1.05 & 0.50 & 2.81 & 1.25 \\
\hline $\mathrm{Chr}$ & 10.29 & 2.24 & 0.86 & 0.20 & 0.88 & 0.16 & 1.11 & 0.37 & 1.01 & 0.66 & 4.71 & 1.15 \\
\hline $\mathrm{BaA}$ & 7.70 & 1.68 & 0.72 & 0.25 & 1.09 & 0.19 & 0.65 & 0.40 & 1.01 & 0.92 & 4.79 & 1.18 \\
\hline $\mathrm{BbF}$ & 10.56 & 1.83 & 1.13 & 0.37 & 1.07 & 0.21 & 0.92 & 0.34 & 1.16 & 0.81 & 3.59 & 1.37 \\
\hline $\mathrm{BkF}$ & 11.88 & 1.79 & 0.98 & 0.20 & 0.98 & 0.19 & 0.90 & 0.26 & 0.97 & 0.56 & 3.68 & 1.22 \\
\hline $\mathrm{BaP}$ & 6.55 & 3.15 & 0.74 & 0.15 & 0.56 & 0.24 & 0.48 & 0.34 & 0.66 & 0.41 & 3.55 & 1.43 \\
\hline DBahA & 5.82 & 0.72 & 0.91 & 0.17 & 1.10 & 0.32 & 1.10 & 0.35 & 1.11 & 0.72 & 3.81 & 0.96 \\
\hline $\mathrm{B}$ (ghi)P & 6.06 & 0.64 & 1.14 & 0.26 & 1.02 & 0.15 & 0.85 & 0.19 & 1.03 & 0.64 & 3.78 & 0.38 \\
\hline IcP & 7.69 & 1.39 & 1.06 & 0.36 & 1.12 & 0.13 & 1.27 & 0.31 & 1.29 & 1.00 & 4.95 & 0.69 \\
\hline$\Sigma \mathrm{PAH}$ & 135.70 & 0.67 & 14.92 & 0.09 & 16.19 & 0.05 & 15.46 & 0.09 & 16.16 & 0.14 & 61.42 & 0.34 \\
\hline
\end{tabular}

$S D$ standard deviation, Abbr abbreviation

Naphthalene (Nap), Acenaphthylene (Acy), Acenaphthene (Ace), Fluorene (Flu), Phenanthrene (Phe), Anthracene (Ant), Fluoranthene (Flua), Pyrene (Pyr), Chrysene (Chr), Benzo[a]anthracene (BaA), Benzo[b]fluoranthene $(\mathrm{BbF})$, Benzo[k]fluoranthene $(\mathrm{BkF})$, Benzo[a]pyrene $(\mathrm{BaP})$, Dibenzo[ah]anthracene (DBahA), Benzo[ghi]perylene (B(ghi)P), Indeno[123 cd]pyrene (IcP)

eruptions, forest fires, and anthropogenic exercises like coal consumption, consuming petroleum products, biomass consumption for agribusiness, and vehicular developments yet the significant sources are a petroleum product and wood-consuming. It was reported that in normal days' and unlock down 1.0-situation aids of wood burning and fossil fuel are approximately the same, but during different lockdown situations, fossil fuel contribution was low compared to wood burning. This is because of the movement of vehicles and industries shut down, i.e., all activities were closed. The contribution of BC toward various wavelength during numerous circumstances are depicted in the Fig. 5.

\subsubsection{Source appropriation of PAHs}

As per an ongoing investigation of PAHs, the symptomatic proportion (DR) examination strategy has been utilized for PAHs' source division (Tobiszewski and Namieśnik 2012). The proportion of IcP/(IcP + B(ghi)P), Flua/(Flua + Pyr), BaA/(BaA + Chr), BaP/B(ghi)P, and Ant/(Ant + Phe) was utilized to recognize the wellsprings of PAHs in the air. The proportion of $\mathrm{IcP} /(\mathrm{IcP}+\mathrm{B}(\mathrm{ghi}) \mathrm{P})$ is a pointer of petrogenic, oil-consuming, and biomass coal ignition source. Proportion esteem $<0.2$ and $>0.5$ characteristic of Petrogenic and biomass burning. The proportion of esteem lies between the scope of $0.2-0.5$ the source will demonstrate the oil burning (Ravindra et al. 2008). The proportion estimation of IcP/(IcP + B (ghi) P) was determined 0.54 before lockdown and 0.49 during the lockdown period, which 


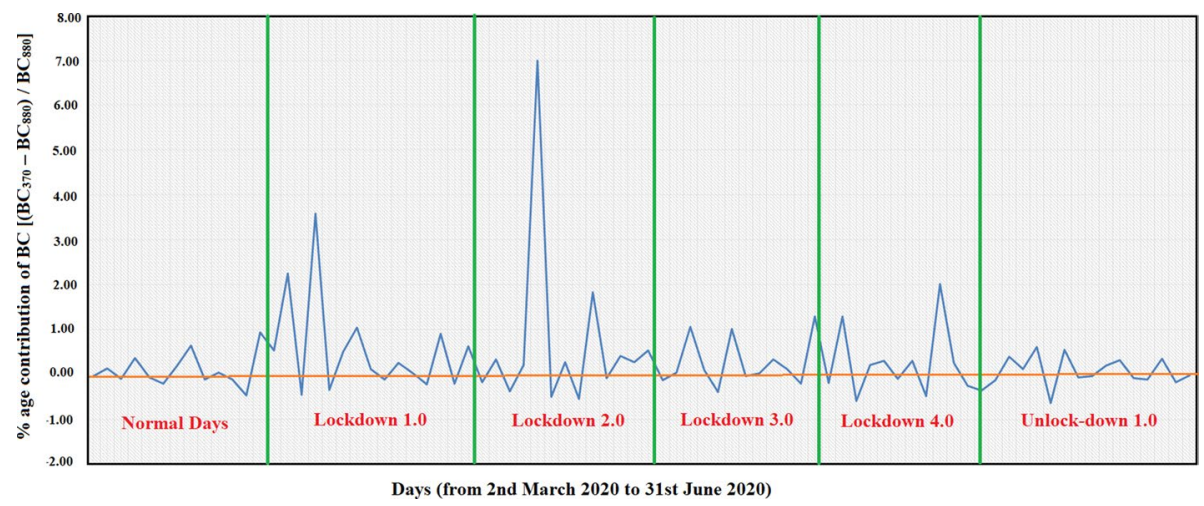

Fig. 5 Fractional contribution of BC measured at $370 \mathrm{~nm}$ and $880 \mathrm{~nm}$ at six different situations i.e., normal days, lockdown 1.0, lockdown 2.0, lockdown 3.0, lockdown 4.0, and unlock down 1.0-situations at Sakchi, Jamshedpur

recommended the outflow from biomass and coal ignition over the investigation site. On the off chance that the proportion of Flua/(Flua + Pyr) is $<0.1$ the characteristic source is Unburned oil/Petrogenic, if esteem saw between 0.4 and 0.5 , the source is petroleum derivative ignition if esteem watched $>0.5$ the source distinguished as coal burning and biomass (Yunker et al. 2002; De La Torre-Roche et al. 2009). In this current investigation, the proportion of Flua/(Flua + Pyr) was seen 0.55 Before lockdown and 0.53 during the lockdown period recommending PAHs emanation from biomass and coal burning. The proportion of $\mathrm{BaA} /(\mathrm{BaA}+\mathrm{Chr})$ is $<0.2$ and $>0.35$ demonstrates ignition and petrogenic source (Yunker et al. 2002; Tobiszewski and Namiesnik 2012). BaA/(BaA + Chr) proportion esteem was seen to be 0.42 and 0.45 before lockdown and during the lockdown period, separately, proposing the coal ignition and biomass source. $\mathrm{BaP} / \mathrm{B}($ ghi) $\mathrm{P}$ proportion determines traffic emanation, $<0.6$ esteem shows non-traffic source and worth $>0.6$ demonstrates the traffic wellspring of discharge. $\mathrm{BaP} / \mathrm{B}$ (ghi)P proportion esteem was determined 1.19 before the lockdown period and 0.56 during the lockdown period recommending traffic source before lockdown and non-traffic source during the lockdown. The proportion of Ant/(Ant + Phe) characteristic of pyrogenic and petrogenic sources. The off chance that the worth discovered $<0.1$ assigns petrogenic and $>0.1$ shows pyrogenic sources (Pies et al. 2008). Insect/ (Ant + Phe) proportion esteem was found to be 0.50 and 0.46 before lockdown and during lockdown period individually, proposing the pyrogenic source. The entire count of indicative proportion investigation has appeared in Table 4.

The Diagnostic proportion examination inferred that biomass, vehicle emanation, and coal consumption were essential drivers of PAHs before the lockdown period. Yet, during the lockdown period, the outflow from consuming biomass and coal was a significant supporter of PAHs.

\subsection{Backward trajectories analysis}

Backward trajectory analysis is a model to explain the transportation routes of air pollutants. It also determines the direction of airflow to describe the possible region of sources before reaching a specific target position. The back trajectories were calculated for two situations, i.e., normal days and different lockdown situations (from lockdown 1.0 to lockdown 
4.0) along with unlock down 1.0. The overall trajectories were prepared using a global environmental dataset online program NCEP (National Centers for Environmental Prediction) Climate Forecast System and Meteorological Data Explorer developed by Center for Global Environmental Research (CGER), Japan and Igor software. Backward trajectories were calculated at different heights (altitude) from 0 to $4000 \mathrm{~m}$ with an other color band. The fire count data downloaded from NASA FIRMS (https://firms.modaps.eosdis.nasa. gov/data/download/DL_FIRE_M6_76896.zip). The fire count data were also incorporated along with back trajectories in Fig. 6. The back trajectory analysis indicated that the air mass (air pollutants) originating from different places from different heights to enter the target places. According to the backward trajectory analysis model, the air-born particulate matter migrated from the northeast part of our country during normal days. Maximum air particulate mass was coming from the Himalayan region, and little air particulate mass was coming from the Bay of Bengal $(\mathrm{BoB})$. It was likewise reported that some air particulate mass was traveled from western countries such as Iran, Afghanistan, and Pakistan, and some air particulate mass was migrated from Nepal and Sikkim as shown in Fig. 6a. It was seen that the air-born particulate matter migrated from the northeast part of, the Indian Ocean, the northern part of our country as well as BoB. The maximum air particulate mass was migrated from western countries mainly from Afghanistan and Pakistan. But the height of trajectories is moderate during lockdown situations (from lockdown 1.0 to lockdown 4.0) and unlock down situations as shown in Fig. 6 b.

\subsection{Health risk assessment of $B C$ and PAHs}

In the current study, we tried to report the health risk assessment expressed in three different situations i.e., normal days, different lockdown situations (from lockdown 1.0 to lockdown 4.0), and unlock down 1.0 situations at Sakchi, Jamshedpur city. The summary of health risk assessment indicated in an identical number of PSC for an individual period of investigation as shown in Table 3. We consider that the day to a daily exposure level of $\mathrm{BC}$ for the people living in Jamshedpur city was equivalent to the day-to-day mean $\mathrm{BC}$ (balance load concerning the background $\mathrm{BC}$ ) level. The $\mathrm{BC}_{\mathrm{bac}}$ concentration level was calculated as the 1.25th percentile of $\mathrm{BC}_{\text {rep }}$ concentrations for the datasets (Rupakheti et al. 2017) at three different situations i.e., $6.72 \mu \mathrm{g} \mathrm{m}^{-3}$ (normal days), $1.14 \mu \mathrm{g} \mathrm{m}^{-3}$ (during different lockdown situations) and $3.13 \mu \mathrm{g} \mathrm{m}^{-3}$ (during unlock down 1.0-situation) for
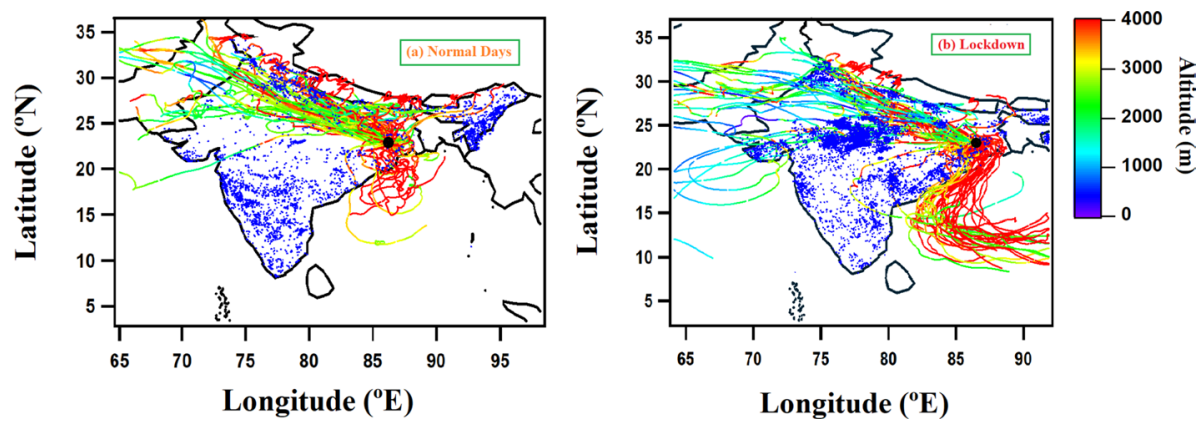

Fig. 6 7-days air mass back trajectories as well as fire count graph on the two different situations a normal days and $\mathbf{b}$ different lockdown and unlock down situations, at an altitude level of $500 \mathrm{~m}$ above ground level, over the sampling side 
Table 3 The health risk estimates of $\mathrm{BC}$ communicated into equivalent numbers of PSC per day concerning four various health issues

\begin{tabular}{llll}
\hline Parameters & Normal Days & $\begin{array}{l}\text { Lockdown } \\
(1.0-4.0)\end{array}$ & Unlock down 1.0 \\
\hline CVM & 4.81 & 2.69 & 4.51 \\
LC & 9.79 & 5.48 & 9.17 \\
LBW & 8.62 & 4.82 & 8.07 \\
PLEDSC & 19.66 & 11 & 18.41 \\
\hline
\end{tabular}

PSC passively smoked cigarettes, $C V M$ cardiovascular mortality, $L C$ lung cancer, $L B W$ low birth weight, $P L F D S C$ percentage lung function decrement of school-aged children

Table 4 Health risk assessment due to PAHs exposure to children and adults over the study area

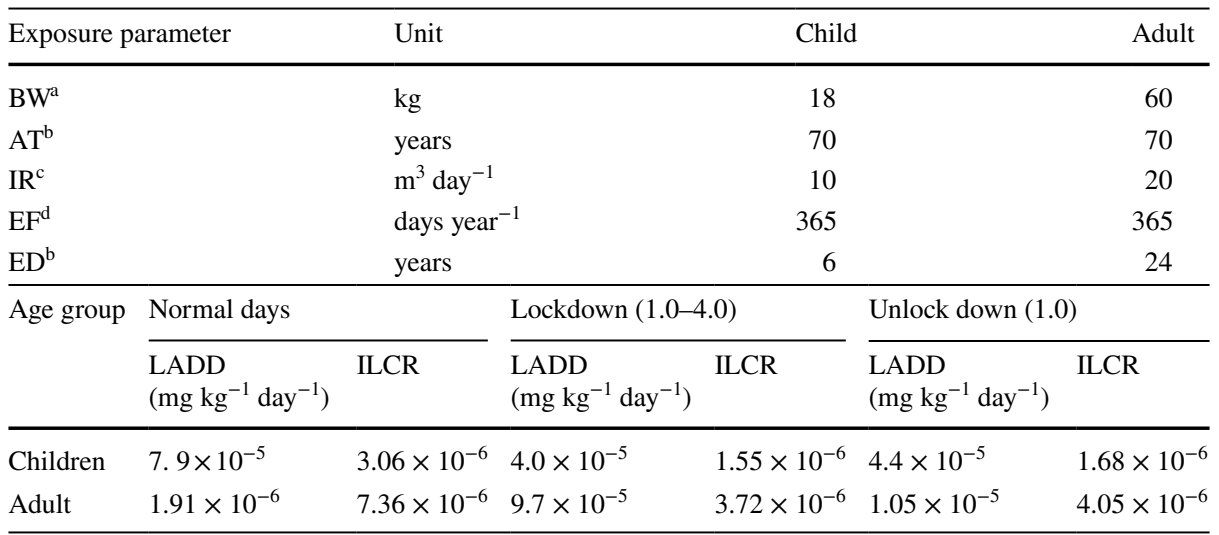

${ }^{\mathrm{a}} \mathrm{ICMR}(2009)$

${ }^{\mathrm{b}}$ Ferreira-Baptista and De-Miguel (2005)

${ }^{\mathrm{c}}$ Soltani et al. (2015)

${ }^{\mathrm{d}}$ Kumar et al. (2013)

${ }^{\mathrm{e}}$ USEPA (2011)

Jamshedpur city in this study. On normal days, the health risk assessment of BC concentration was reported as high as 4.81, 9.79, 8.62, and 19.66 passive cigarettes comparable concerning the risk of CVM, LC, LBW, and PLEDSC, respectively. And during different lockdown situations (from lockdown 1.0 to lockdown 4.0) and unlock down 1.0-situation, the health risk assessment of $\mathrm{BC}$ concentration was reported as low as $2.69,5.48,4.82,11$ and $4.51,9.17,8.07,18.41$ passive cigarettes comparable concerning the risk of CVM, LC, LBW, and PLEDSC, respectively. It was noticed that the health risk issue is higher on normal days compared to the COVID-19 pandemic (during different lockdown situations and unlock down 1.0-situation).

In this recent study, the health risk of 16 USEPA priority PAHs was analyzed. The LADD'S value for carcinogenic PAHs for an adult was found to be $1.91 \times 10^{-6}, 9.7 \times 10^{-5}$ and $1.05 \times 10^{-5} \mathrm{mg} \mathrm{kg}^{-1} \mathrm{day}^{-1}$ over the study site during normal days, different lockdown situations (from lockdown 1.0 to lockdown 4.0) and unlock down 0.1 situations, respectively. Established on LADD value over the study spot, ILCR value for an adult was estimated at $7.36 \times 10^{-6}, 3.72 \times 10^{-6}$ and $4.05 \times 10^{-6}$ during normal days, different lockdowns 
and unlock down 0.1 situations, respectively. During normal days, different lockdown situations and unlock down 0.1 situations, the LADD value for children was found to be $7.9 \times 10^{-5}, 4.0 \times 10^{-5}$ and $4.4 \times 10^{-5} \mathrm{mg} \mathrm{kg}^{-1} \mathrm{day}^{-1}$, respectively. ILCR value for children was estimated at $3.06 \times 10^{-6}, 1.55 \times 10^{-6}$ and $1.68 \times 10^{-6}$ during normal days, different lockdown and unlock down situations, respectively. Furthermore, the excess lifetime cancer risk (ELCR) was estimated by some ILCR for adult and ILCR values for the child over the study sites. The ELCR values for normal days, different lockdown situations and during unlock down situations were $10.42 \times 10^{-6}, 5.27 \times 10^{-6}$, and $5.73 \times 10^{-6}$, respectively. The ELCR value were lies between the acceptable limit $10^{-6}-10^{-4}$ specified by regulatory agency USEPA (USEPA. 1989) during normal days, different lockdown, and unlock down situations. A concise of the health hazards assessment of PAHs has been given in Table 4. The result showed that the risk level was acceptable over the study site during normal days, different lockdown and unlock down situations.

\section{Conclusion}

Measurements of $\mathrm{BC}$ mass concentrations, PAHs concentration, and $\mathrm{PM}_{2.5}$ were reported in different situations i.e., normal days, lockdown-1.0, lockdown-2.0, lockdown-3.0, lockdown-4.0, and unlock down-1.0-situation. The averaged BC mass concentrations were $9.40 \pm 2.73 \mu \mathrm{g} \mathrm{m}^{-3}, 1.85 \pm 0.36 \mu \mathrm{g} \mathrm{m}^{-3}, 2.24 \pm 0.55 \mu \mathrm{g} \mathrm{m}^{-3}, 2.69 \pm 0.71 \mu \mathrm{g} \mathrm{m}^{-3}, 4.11 \pm 1.02$ $\mu \mathrm{g} \mathrm{m} \mathrm{m}^{-3}$, and $5.64 \pm 1.68 \mu \mathrm{g} \mathrm{m}^{-3}$ during normal days, lockdown-1.0, lockdown-2.0, lockdown-3.0, lockdown-4.0, and unlock down-1.0 situation, respectively, at Sakchi, Jamshedpur city. The averaged $\mathrm{PM}_{2.5}$ mass concentrations were $136.26 \pm 32.16 \mu \mathrm{g} \mathrm{m}^{-3}$, $41.39 \pm 8.33 \mu \mathrm{g} \mathrm{m}^{-3}, 43.75 \pm 12.45 \mu \mathrm{g} \mathrm{m}^{-3}, 45.50 \pm 9.14 \mu \mathrm{g} \mathrm{m}^{-3}, 52.99 \pm 16.21 \mu \mathrm{g} \mathrm{m}^{-3}$, and $86.48 \pm 15.77 \mu \mathrm{g} \mathrm{m}^{-3}$ during normal days, lockdown-1.0, lockdown-2.0, lockdown-3.0, lockdown-4.0, and unlock down-1.0-situation, respectively, at Sakchi, Jamshedpur city. BC mass concentrations and $\mathrm{PM}_{2.5}$ concentration varies from $1.07 \mu \mathrm{g} \mathrm{m}^{-3}$ to $16.45 \mu \mathrm{g} \mathrm{m}^{-3}$ and $25.39 \mu \mathrm{g} \mathrm{m}^{-3}$ to $205.67 \mu \mathrm{g} \mathrm{m}^{-3}$ during study period. During normal days, BC mass concentration and PAHs concentration as high compared to different lockdown and unlock down situations and moderate during unlock down situations; neither is higher than normal days nor low compared to different lockdown situations. The average PAH concentrations were $135.70 \pm 24.60 \mathrm{ng} \mathrm{m}^{-3}, 14.92 \pm 3.84 \mathrm{ng} \mathrm{m}^{-3}, 16.19 \pm 2.81 \mathrm{ng} \mathrm{m}^{-3}, 15.46 \pm 5.85 \mathrm{ng} \mathrm{m}^{-3}$, $16.16 \pm 10.56 \mathrm{ng} \mathrm{m}^{-3}$, and $61.42 \pm 15.95 \mathrm{ng} \mathrm{m}^{-3}$ during normal days, lockdown-1.0, lockdown-2.0, lockdown-3.0, lockdown-4.0, and unlock down-1.0 situation, respectively, at study side. PAH concentration varies from 12.81 to $135.70 \mathrm{ng} \mathrm{m}^{-3}$ during the study period. PAHs concentration was low during different lockdown situations because, during lockdown situations, all the activities were closed. The industry work, transport work, construction work, traffic movement, etc., was shut down due to the COVID-19 pandemic. As a result, air pollutants' emission was less compared to normal days in Jamshedpur city atmosphere. According to the diagnostic ratio analysis of $\mathrm{BC}$, it was noticed that the influence of wood burning as well as fossil fuel was the same in the normal days and unlock down. It was also reported that the fossil fuel contribution was low as compared to wood burning during different lockdown situations. The diagnostic ratio analysis of PAHs suggests that biomass, coal burning and vehicle emission were primary causes of PAHs during the study period. The summary of health risk assessment indicated an equal number of PSC for an individual month of investigation. The health hazard assessment of BC concentration was reported as 4.81, 9.79, 8.62, 19.66; 2.69, 5.48, 4.82, 11 and 4.51, 9.17, 8.07, 
18.41 during normal days, lockdown (from lockdown-1.0 to lockdown-4.0) and unlock down-1.0 situations in Sakchi, Jamshedpur city, the passive cigarettes comparable concerning the risk of CVM, LC, LBW, and PLEDSC, respectively. The excess lifetime cancer risk (ELCR) value was reported to be $10.42 \times 10^{-6}, 5.27 \times 10^{-6}$, and $5.73 \times 10^{-6}$ for normal days, different lockdown situations (from LD 1.0 to LD 4.0) and during unlock down (ULD 1.0) situation.

Acknowledgements The present study was supported by the Science \& Engineering Research Board (SERB) (Grant No. ECR1) Government of India. The Sanction Order number of the project is ECR/2017/000597. The author thanks NASA FIRMS (Fire Information for Resource Management System), GIOVANNI NASA, Fire Archive for fire count data by Moderate Resolution Imaging Spectroradiometer (MODIS) C6. The Meteorological Data Explorer developed by the Center for Global Environmental Research (CGER), Japan (METEX, http://db.cger.nies.go.jp/metex/trajectory.html) and for the provision of trajectories used in the publication.

Funding Science \& Engineering Research Board (SERB) Government of India. The Sanction Order number of the project is ECR/2017/000597.

\section{Compliance with ethical standards}

Conflict of interest The authors declare that they have no known competing financial interests or personal relationships that could have appeared to influence the work reported in this paper.

\section{References}

Allen, G. A., Lawrence, J., \& Koutrakis, P. (1999). Field validation of a semicontinuous method for aerosol black carbon (aethalometer) and temporal patterns of summertime hourly black carbon measurements in southwestern PA. Atmospheric Environment, 33, 817-823.

Arey, J., \& Atkinson, R. (2003). Photochemical reactions of PAH in the atmosphere. In P. E. T. Douben (Ed.), PAHs: An ecotoxicological perspective (pp. 47-63). New York, NY: John Wiley and Sons Ltd.

Baek, S. O., Field, R. A., Goldstone, M. E., Kirk, P. W., Lester, J. N., \& Perry, R. (1991). A review of atmospheric polycyclic aromatic hydrocarbons: sources, fate and behavior. Water, Air, and Soil Pollution, 60, 79-300.

Belis, C. A., Karagulian, F., Larsen, B. R., \& Hopke, P. K. (2013). Critical review and metaanalysis of ambient particulate matter source apportionment using receptor models in Europe. Atmospheric Environment, 69, 94-108.

Boeuf, B., Fritsch, O., \& Martin-Ortega, J. (2016). Undermining European environmental policy goals? The EU water framework directive and the politics of exemptions. Water, 8, 388.

Briggs, N. L., \& Long, C. M. (2016). Critical review of black carbon and elemental carbon source apportionment in Europe and the United States. Atmospheric Environment, 144, 409-427.

Bull, K. (2003). Protocol to the 1979 convention on long-range trans boundary air pollution on persistent organic pollutants: The 1998 agreement for the UNECE region, Geneva.

Cachier, H. (1995). Combustion carbonaceous aerosols in the atmosphere: implications for ice core studies. In J. D. Robert (Ed.), Ice core studies of global biogeochemical cycles (pp. 313-346)., NATO ASI Series Berlin: Springer.

Chen, S. C., \& Liao, C. M. (2006). Health risk assessment on human exposed to environmental polycyclic aromatic hydrocarbons pollution sources. Science of the Total Environment, 366, 112-123.

Cristale, J., Silva, F. S., Zocolo, G. J., \& Marchi, M. R. R. (2012). Influence of sugarcane burning on indoor/ outdoor PAH air pollution in Brazil. Environmental Pollution, 169, 210-216.

De La Torre-Roche, R. J., Lee, W.-Y., \& Campos-Díaz, S. I. (2009). Soil-borne polycyclic aromatic hydrocarbons in El Paso, Texas: analysis of a potential problem in the United States/Mexico border region. Journal of Hazardous Materials, 163, 946-958.

De Prins, S., Dons, E., Van Poppel, M., IntPanis, L., Van de Mieroop, E., Nelen, V., et al. (2014). Airway oxidative stress and inflammation markers in exhaled breath from children are linked with exposure to black carbon. Environment International, 73, 440-446. 
Favez, O., Haddad, E. I. I., Piot, C., Boreave, A., Abidi, E., Marchand, N., et al. (2010). Inter-comparison of source apportionment models for the estimation of wood burning aerosols during wintertime in an Alpine city (Grenoble, France). Atmospheric Chemistry and Physics, 10, 5295-5314.

Ferreira-Baptista, L., \& De-Miguel, E. (2005). Geochemistry and risk assessment of street dust in Luanda: Angola. A tropical urban environment. Atmospheric Environment, 39, 4501-4512.

Florou, K., Papanastasiou, D. K., Pikridas, M., Kaltsonoudis, C., Louvaris, E., Gkatzelis, G. I., et al. (2017). The contribution of wood burning and other pollution sources to wintertime organic aerosol levels in two Greek cities. Atmospheric Chemistry and Physics, 17, 3145-3163.

Hansen, A. D. A., Rosen, H., \& Novakov, T. (1984). The aethalometer: an instrument for the realtime measurements of optical absorption by aerosol particles. Science of the Total Environment, 36, 191-196.

IARC. (1984). Polynuclear aromatic compounds. Part 1. Chemical environmental and experimental data IARC monographs on the evaluation of the carcinogenic risk of chemicals to humans, vol. 32. International Agency for Research on Cancer, Lyon, France.

ICMR. (2009). Nutrient requirements and recommended dietary allowances for Indians. A report of the expert group of the Indian Council of Medical Research Hyderabad, India: National Institute of Nutrition.

Janssen, N. H., Janssen, N., \& Gerlofs, N. M. (2012). Health effects of black carbon. Copenhagen: World Health Organization.

Kelly, F. J., \& Fussell, J. C. (2015). Air pollution and public health: emerging hazards and improved understanding of risk. Environmental Geochemistry and Health, 37, 631-649.

Kumar, M., Furumai, H., Kurisu, F., \& Kasuga, I. (2013). Tracing source and distribution of heavy metals in road dust: Soil and soak away sediment through speciation and isotopic fingerprinting. Geoderma, 211-212, 8-17.

Larsen, B. R., Gilardoni, S., Stenstrom, K., Niedzialek, J., Jimenez, J., \& Belis, C. A. (2012). Sources for PM air pollution in the Po Plain, Italy: II. Probabilistic uncertainty characterization and sensitivity analysis of secondary and primary sources. Atmospheric Environment, 50, 203-213.

Lau, K. M., Kim, M. K., Kim, K. M., \& Lee, W. S. (2010). Enhanced surface warming and accelerated snow melt in the Himalayas and Tibetan Plateau induced by absorbing aerosols. Environmental Research Letters, 5, 025204.

Liu, Y., Yan, C., \& Zheng, M. (2018). Source apportionment of black carbon during winter in Beijing. Science of the Total Environment, 618, 531-541.

Magalhaes, S., Baumgartner, J., \& Weichenthal, S. (2018). Impacts of exposure to blackcarbon, elemental carbon, and ultrafine particles from indoor and outdoor sources on blood pressure in adults: a review of epidemiological evidence. Environmental Research, 161, 345-353.

Mostert, M. M. R., Ayoko, G. A., \& Kokot, S. (2010). Application of chemometrics to analysis of soil pollutants. TrAC Trends in Analytical Chemistry, 29, 430-435.

Muller, R. A., \& Muller, E. A. (2013). Air pollution and cigarette equivalence. Berkeley Earth 47.

Niranjan, R., \& Thakur, A. K. (2017). The toxicological mechanisms of environmental soot (black carbon) and carbon black: Focus on oxidative stress and inflammatory pathways. Frontiers in Immunology, 8, 763.

Nisbet, I. C. T., \& Lagoy, P. K. (1992). Toxic equivalency factors (TEFs) for polycyclic aromatic hydrocarbons (PAHs). Regulatory Toxicology and Pharmacology, 16(3), 290-300.

Oberg, M., Jaakkola, M. S., Prüss-Üstün, A., Schweizer, C., \& Woodward, A. (2010). Second Hand Smoke, Assessing the Environmental Burden of Disease at National and Local Levels, vol. 18. World Health Organization, Geneva, Environmental Burden of Disease Series. http://www.who.int/ quantifying_ehimpacts/publications/SHS.pdf.

Ohara, T., Akimoto, H., Kurokawa, J., Horii, N., Yamaji, K., Yan, X., et al. (2007). An Asian emission inventory of anthropogenic emission sources for the period 19802020. Atmospheric Chemistry and Physics, 7, 4419-4444. https://doi.org/10.5194/acp-7-4419-2007.

Pani, S. K., Wang, S. H., Lin, N. H., Chantara, S., Lee, C. T., \& Thepnuan, D. (2020). Black carbon over an urban atmosphere in northern peninsular Southeast Asia: Characteristics, source apportionment, and associated health risks. Environmental Pollution, 259(2020), 113871.

Peng, C., Chen, W. P., Liao, X. L., Wang, M. E., Ouyang, Z. Y., Jiao, W. T., et al. (2011). Polycyclic aromatic hydrocarbons in urban soils of Beijing: Status, sources, distribution and potential risk. Environmental Pollution, 159, 802-808.

Pies, C., Hoffmann, B., Petrowsky, J., Yang, Y., Ternes, T. A., \& Hofmann, T. (2008). Characterization and source identification of polycyclic aromatic hydrocarbons (PAHs) in river bank soils. Chemosphere, 72, 1594-1601. 
Prasad, P., Raman, M. R., Ratnam, M. V., Chen, W. N., Rao, S. V. B., Gogoi, M. M., et al. (2018). Characterization of atmospheric black carbon over a semi-urban site of Southeast India: Local sources and long-range transport. Atmospheric Research, 213, 411-421.

Ramanathan, V., \& Carmichael, G. (2008). Global and regional climate changes due to black carbon. Nature Geoscience, 1, 221-227.

Rastogi, N., Singh, A., Sarin, M. M., \& Singh, D. (2016). Temporal variability of primary and secondary aerosols over northern India: Impact of biomass burning emissions. Atmospheric Environment, $125,396-403$

Ravindra, K., Sokhi, R., \& Van Grieken, R. (2008). Atmospheric polycyclic aromatic hydrocarbons: Source attribution, emission factors and regulation. Atmospheric Environment, 42, 2895-2921.

Riemer, N., West, M., Zaveri, R., \& Easter, R. (2010). Estimating black carbon aging time-scales with a particle-resolved aerosol model. Journal of Aerosol Science, 41, 143-158.

Rose, D., Gunthe, S. S., Su, H., Garland, R. M., Yang, H., Berghof, M., et al. (2011). Cloud condensation nuclei in polluted air and biomass burning smoke near the mega-city Guangzhou, China-Part 2: Size-resolved aerosol chemical composition, diurnal cycles, and externally mixed weakly CCNactive soot particles. Atmospheric Chemistry and Physics, 11, 2817-2836. https://doi.org/10.5194/ acp-11-2817-2011.

Rothman, K. J., Greenland, S., \& Lash, T. L. (2008). Modern epidemiology (pp. 53-77). Philadelphia, PA: Wolters Kluwer/Lippincott Williams \& Wilkins.

Rupakheti, D., Adhikary, B., Praveen, P. S., Rupakheti, M., Kang, S., Mahata, K. S., et al. (2017). Premonsoon air quality over Lumbini, a world heritage site along the Himalayan foothills. Atmospheric Chemistry and Physics, 17, 11041-11063.

Soltani, N., Keshavarzi, B., Moore, F., Tavakol, T., Lahijanzadeh, A. R., Jaafarzadeh, N., et al. (2015). Ecological and human health hazards of heavy metals and polycyclic aromatic hydrocarbons (PAHs) in street dust of Isfahan metropolis, Iran. Science of the Total Environment, 505, 712-723.

Srivastava, A. K., Singh, S., Pant, P., \& Dumka, U. C. (2012). Characteristics of black carbon over Delhi and Manora Peak-a comparative study. Atmospheric Science Letters. https://doi.org/10.1002/ asl.386,223-230(July).

Thepnuan, D., Chantara, S., Lee, C. T., Lin, N. H., \& Tsai, Y. I. (2019). Molecular markers for biomass burning associated with the characterization of PM2.5 and component sources during dry season haze episodes in Upper South East Asia. Science of the Total Environment, 658, 708-722.

Tobiszewski, M., \& Namieśnik, J. (2012). PAH diagnostic ratios for the identification of pollution emission sources. Environmental Pollution, 162, 110-119.

USEPA. (2011). Exposure factors handbook edition. EPA/600/R-09/052F. Washington, DC: National Center for Environmental Assessment, Office of Research and Development, U.S. Environmental Protection Agency 20460.

Vadrevu, K. P., Lasko, K., Giglio, L., \& Justice, C. (2015). Vegetation fires, absorbing aerosols and smoke plume characteristics in diverse biomass burning regions of Asia. Environmental Research Letters, 10, 105003. https://doi.org/10.1088/1748-9326/10/110/105003.

Van der Zee, S. C., Fischer, P. H., \& Hoek, G. (2016). Air pollution in perspective: health risks of air pollution expressed in equivalent numbers of passively smoked cigarettes. Environmental Research, 148, $475-483$.

Venkataraman, C., Habib, G., Kadamba, D., Shrivastava, M., Leon, J.-F., Crouzille, B., et al. (2006). Emissions from open biomass burning in India: Integrating the inventory approach with high resolution Moderate Resolution Imaging Spectroradiometer (MODIS) active-fire and land cover data. Global BiogeochemicalCycles, 20, GB2013. https://doi.org/10.1029/2005GB002547.

Venkataraman, C., Lyons, J. M., \& Friedlander, S. K. (1994). Size distributions of polycyclic aromatic hydrocarbons and elemental carbon. 1. Sampling, measurement methods, and source characterization. Environmental Science and Technology, 28, 555-562.

Wang, Y., Hopke, P. K., \& Utell, M. J. (2011). Urban-scale spatial-temporal variability of black carbon and winter residential wood combustion particles. Aerosol and Air Quality Research, 11, 473-481.

Wang, Z., Li, K., Lambert, P., \& Yang, C. (2007). Identification, characterization and quantitation of pyrogenic polycyclic aromatic hydrocarbons and other organic compounds in tire fire products. Journal of Chromatography A, 1139(1), 14-26.

Weingartner, E., Saathoff, H., Schnaiter, M., Streit, N., Bitnar, B., \& Baltensperger, U. (2003). Absorption of light by soot particles, determination of the absorption coefficient by means of aethalometers. Journal of Aerosol Science, 34, 1445-1463.

WHO. (2020b). World Health Organization, Coronavirus Disease (COVID-2019) Situation Reports- Situation Report - 116; [accessed 2020 May 15]. https:/www.who.int/docs/default-source/coronaviruse/ situation-reports/20200515-covid-19-sitrep-116.pdf?sfvrsn=8dd60956_2. 
WHO (World Health Organization). (2003). Health Aspects of Air Pollution with Particulate Matter, Ozone and Nitrogen Dioxide. http://www.euro.who.int/document/e79097.

WHO (World Health Organization). (2014). Burden of Disease from Air Pollution. http://www.who.int/phe/ health_topics/outdoorair/databases/FINAL_HAP_AAP_BoD_24March2014.pdf, 02.02.16.

World Health Organization. (2020a). Novel coronavirus - Thailand (ex-China).

Wu, J., Lu, J., Min, X., \& Zhang, Z. (2018). Distribution and health risks of aerosol black carbon in a representative city of the Qinghai-Tibet Plateau. Environmental Science and Pollution Research, 25(20), 19403-19412.

$\mathrm{Xu}$, S., Liu, W., \& Tao, S. (2006). Emission of polycyclic aromatic hydrocarbons in China. Environmental Science and Technology, 40, 702-708.

Yu, Y., Guo, H., Liu, Y., Huang, K., Wang, Z., \& Zhan, X. (2008). Mixed uncertainty analysis of polycyclic aromatic hydrocarbon inhalation and risk assessment in ambient air of Beijing. Journal of Environmental Science, 20, 505-512.

Yunker, M., MacDonald, R., Vingarzan, R., Mitchell, R., Goyette, D., \& Sylvestre, S. (2002). PAHs in the Fraser River basin: a critical appraisal of PAH ratios as indicators of PAH source and composition. Organic Geochemistry, 33, 489-515.

Zhang, Y. X., \& Tao, S. (2008). Emission of polycyclic aromatic hydrocarbons (PAHs) from indoor straw burning and emission inventory updating in China. Annals of the New York Academy of Sciences, 1140, 218-227.

Zotter, P., Herich, H., Gysel, M., El-Haddad, I., Zhang, Y., Močnik, G., et al. (2017). Evaluation of the absorption Ångstrom exponents for traffic and wood burning in the Aethalometer-based source apportionment using radiocarbon measurements of ambient aerosol. Atmospheric Chemistry and Physics, 17, 4229-4249.

Publisher's Note Springer Nature remains neutral with regard to jurisdictional claims in published maps and institutional affiliations. 